Available online at GSC Online Press Directory

GSC Biological and Pharmaceutical Sciences

e-ISSN: 2581-3250, CODEN (USA): GBPSC2

(RESEARCH ARTICLE)

\title{
RP-HPLC method for estimation of tramadol hydrochloride and paracetamol in pharmaceutical formulation
}

\author{
Kumar T Hemant *, Prajna C Kasi Krishna, Rao K Varaprasad and Rao Y Srinivasa \\ Vignan Institute of Pharmaceutical Technology, Duvvada, Vishakapatnam, Andhra Pradesh, India.
}

Publication history: Received on 25 May 2019; revised on 18 July 2019; accepted on 22 July 2019

Article DOI: https://doi.org/10.30574/gscbps.2019.8.1.0091

\begin{abstract}
A simple, rapid and sensitive RP-HPLC method was developed for the quantitative determination of tramadol hydrochloride and paracetamol in combined tablet dosage form. The chromatographic analysis was carried out on enable C18G column (250 x $4.6 \mathrm{~mm}, 5 \mu \mathrm{m})$ with mobile phase containing $1 \%$ glacial acetic acid: acetonitrile (50:50 $\mathrm{v} / \mathrm{v}$ ). The flow rate of mobile phase was $1.0 \mathrm{~mL} / \mathrm{min}$ and effluents were monitored at $272 \mathrm{~nm}$. The retention times of tramadol hydrochloride and paracetamol were $2.032 \mathrm{~min}$ and $2.711 \mathrm{~min}$, respectively. The proposed method was validated with respect to linearity, accuracy, precision, specificity and robustness. The method was found to simple, rapid and sensitive and was successfully applied to the estimation of tramadol hydrochloride and paracetamol in combined dosage form.
\end{abstract}

Keywords: RP-HPLC; Tramadol hydrochloride; Paracetamol

\section{Introduction}

Tramadol hydrochloric (TRD) ( \pm )-cis-2-(dimethylamino) methyl-1-(3-methoxy-phenyl) cyclohexanol hydrochloride (Figure 1), a synthetic analogue of codeine, is a centrally acting analgesic agent. It has been used since 1977 for the relief of severe physical pain and has been the most widely sold opioid analgesic drug in the world.

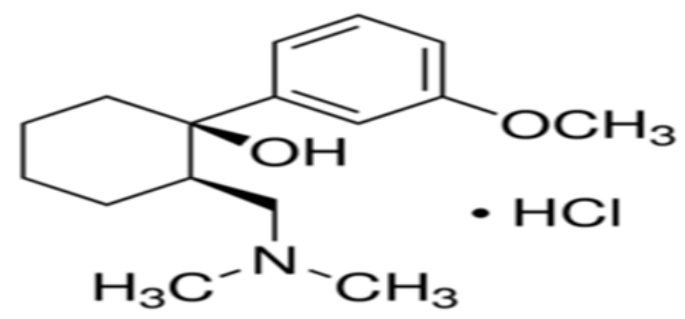

Figure 1 Structure of tramadol hydrochloride

The complementary and synergistic actions of two enantiomers improve the analgesic efficacy and tolerability profile of the racemate. Tramadol analgesic effects are also partially reversed by $\alpha_{2}$ adrenergic receptor antagonists and the $5-\mathrm{HT}_{3}$ receptor antagonist. Tramadol has inhibitory actions on the 5- $\mathrm{HT}_{2}$ receptor [1].

Paracetamol (PCM) is chemically 4-hydroxy acetanilide. It is a weak inhibitor of peripheral cyclooxygenase and its analgesic effects may arise from inhibition of prostanoid synthesis in the CNS. The antipyretic effects of paracetamol

\footnotetext{
${ }^{*}$ Corresponding author

E-mail address: hemkar_pharma@yahoo.co.in
} 
are due to its action at the level of the hypothalamus to reduce pyrogen-initiated alterations in body temperature by inhibiting prostaglandin synthesis [2].

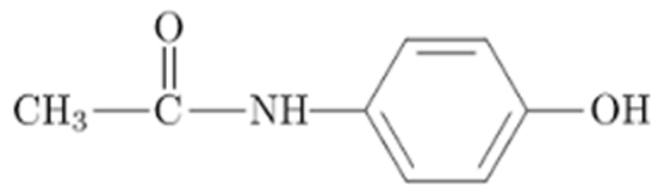

Figure 2 Structure of paracetamol

Paracetamol (PCM) is thought to act primarily in the CNS, increasing the pain threshshold by inhibiting both isoforms of cyclooxygenase, COX-1 and COX-2, enzymes involved in prostaglandin (PG) synthesis. Unlike NSAIDS, Paracetmol does not inhibit cyclooxygenase in peripheral tissues and thus has no peripheral anti-inflammatory effects. Paracetmol indirectly blocks COX, and that this blockade is ineffective in the presence of perioxides. The drug selectively blocks a variant of the COX enzyme that is different from the known variant COX-1 and COX-2. Literature review reveals that simultaneous determination of PCM and TH content in tablets can be achieved by spectrophotometry, [3-9] high performance thin layer chromatography [10-13] and reverse phase high performance liquid chromatography [14-18]. Among the different analytical equipments and techniques, Reverse Phase High Performance Liquid Chromatography (RP-HPLC) stands out due to its resolution, specificity, accuracy, precision and cost effectiveness. The mobile phase used in the HPLC methods mentioned above is a mixture of either methanol or acetonitrile along with buffer. The important disadvantages of using methanol are the requirement of poison license to purchase it, higher noise at lower ultraviolet wavelengths (lesser than $250 \mathrm{~nm}$ ), and higher column pressures. The use of buffer causes salt deposition effect on HPLC parts and frequent washings are required after its use. The advantages of using acetonitrile include greater sensitivity for analysis at shorter wavelengths, greater elution strength, and less ghost peaking during gradient technique. Another advantage of the present method is that it avoids the use of triethylamine which can alter the column in a way that is not easily reversible and retention time for paracetamol and tramadol hydrochloride was found less in which the consumption of moile phase is less. The present study describes the development and validation of an optimal isocratic RP-HPLC method for simultaneous quantitative estimation of PCM and TRD in tablet formulation.

\section{Material and methods}

\subsection{Instrumentation}

Shimadzu HPLC comprising of LC- 20 AD binary gradient pump, a variable wavelength programmable SPD-20A detector and SCL system controller. A Rheodyne micro-litre syringe fitted with a $20 \mu$ loop was used for injection of sample into the column and data were recorded evaluated by use of LC solutions software.

\subsection{Materials}

Tramadol and paracetmol pure samples were procured as gift samples. Calpol T tablets were procured from the local market. Label claim of calpol T tablets for TRD and Paracetmol were $37.5 \mathrm{mg}$ and $325 \mathrm{mg}$ respectively. Methanol, acetonitrile and glacial acetic acid and water of HPLC grade were purchased from E. Merck and used throughout the experiment.

\subsection{Mobile phase preparation}

$1 \%$ Glacial acetic acid and acetonitrile in the ratio of 50:50 v/v was used as mobile phase. The mobile phase was sonicated for $15 \mathrm{~min}$ in an ultrasonic bath and filtered through nylon membrane disc filter of $0.45 \mu \mathrm{m}$ pore size using a vacuum pump before pumping into the HPLC system. For the preparation of 1\% Glacial acetic acid, $1 \mathrm{ml}$ of glacial acetic acid was taken and dissolved in the $100 \mathrm{ml}$ of HPLC grade water in $100 \mathrm{ml}$ of volumetric flask.

\subsection{Preparation of stock standard solution}

Tramadol hydrochloride (100 mg) and paracetamol (500 mg) were accurately weighed and transferred into $100 \mathrm{ml}$ volumetric flask separately. They were dissolved in $100 \mathrm{ml}$ acetonitrile to obtain $1000 \mu \mathrm{g} / \mathrm{ml} \mathrm{and} 5000 \mu \mathrm{g} / \mathrm{ml}$ concentration of stock solutions respectively. From these stock solution $1 \mathrm{ml}$ each of TRD and PCM were taken into 10 $\mathrm{ml}$ volumetric flasks separately and further diluted with a mobile phase to get $100 \mu \mathrm{g} / \mathrm{ml} \mathrm{and} 500 \mu \mathrm{g} / \mathrm{ml}$ concentrations of TRD and PCM respectively. The solutions were then filtered through $0.45 \mu \mathrm{m}$ Nylon filter. 


\subsection{Preparation of sample solution}

For analysis of drugs, 20 tablets were weighed and triturated in glass mortar and quantity of powder equivalent to $325 \mathrm{mg}$ of paracetamol was transferred to $100 \mathrm{ml}$ volumetric flask and dissolved in sufficient quantity of acetonitrile. It was sonicated for $10 \mathrm{~min}$ and volume was made up to $100 \mathrm{ml}$ to obtain a stock solution of $375 \mu \mathrm{g} / \mathrm{ml}$ of tramadol hydrochloride and $3250 \mu \mathrm{g} / \mathrm{ml}$ of paracetamol. This solution was then filtered through nylon $0.45 \mu \mathrm{m}$ membrane filter. The solution was further diluted with mobile phase to get a concentration of $37.5 \mu \mathrm{g} / \mathrm{ml}$ and $325 \mu \mathrm{g} / \mathrm{ml} \mathrm{of}$ tramadol hydrochloride and paracetamol respectively. This solution was injected 6 times in to the column and chromatograms were recorded and respective peak areas were measured. The contents of TRD and PCM were calculated by using the regression.

\subsection{Chromatographic conditions}

Column

: RP C18G $(250 \times 4.6 \mathrm{~mm}, 5 \mu \mathrm{m}$ particle size $)$

Flow rate

$: 1 \mathrm{ml} / \mathrm{min}$

Detection wavelength

: $272 \mathrm{~nm}$

Injection volume

: $20 \mu \mathrm{l}$

Column temperature

: Ambient.

Run Time

: $10 \min$

Mobile Phase

: Acetonitrile: $1 \%$ Glacial Acetic acid (50: 50 v/v)

Run Mode

: Isocratic

\section{Results and discussions}

\subsection{Optimization of chromatographic conditions}

Several HPLC methods were reported for the estimation of tramadol hydrochloride and paracetamol using methanol, water, acetonitrile and ortho phosphoric acid as mobile phases.With a intention to develop a HPLC method with less retention time for TRD and PCM we tried with acetonitrile and $1 \%$ glacial acetic acid using Enable C18G $(250 \times 4.6$ $\mathrm{mm}$ i.d., $5 \mu$ ) column. Different trails were performed using different proportions of acetonitrile and $1 \%$ glacial acetic acid. The mobile phase containing $1 \%$ glacial acetic acid and acetonitrile in the composition of $50: 50 \mathrm{v} / \mathrm{v}$ was found to be satisfactory and gave symmetric and well resolved peak for TRD and PCM. The retention time of Tramadol hydrochloride and paracetamol was found to be $2.032 \mathrm{~min}$ and $2.711 \mathrm{~min}$. The standard chromatogram was shown in Figure 3.

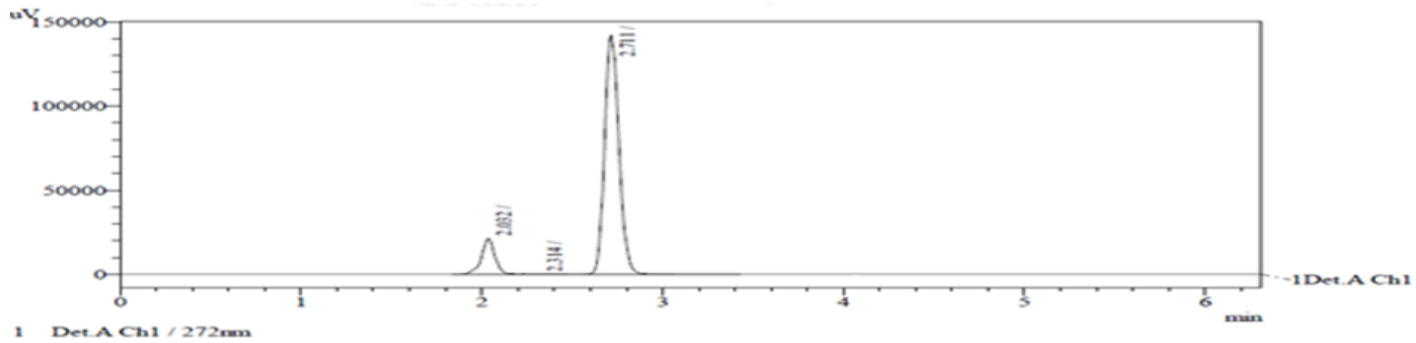

Figure 3 Chromatogram of paracetamol and tramadol hydrochloride

\subsection{Method validation}

The proposed method was validated according to the International Conference on Harmonization (ICH) guidelines [19]. 


\subsubsection{System suitability}

System suitability is used to verify, whether the resolution and reproducibility of the chromatographic system are adequate for analysis to be done. \% RSD on five replicate injections of standards solution was calculated. The results of system suitability for TRD and PCM are shown in Table 1.

Table1 Chromatographic characteristics of system suitability

\begin{tabular}{lll}
\hline PARAMETERS & \multicolumn{2}{c}{ VALUE (Mean* \pm SD) } \\
\cline { 2 - 3 } & TRD & PCM \\
\cline { 2 - 3 } Peak Area & $142611.5 \pm 0.08$ & $3830389 \pm 0.003$ \\
Tailing Factor & $1.25 \pm 0.04$ & $1.12 \pm 0.01$ \\
Theoretical Plate & $4373 \pm 0.06$ & $6738 \pm 0.02$ \\
HETP & $36.3 \pm 0.01$ & $38.7 \pm 0.03$ \\
Retention time & $2.032 \mathrm{~min}$ & $2.711 \mathrm{~min}$ \\
\hline
\end{tabular}

\subsubsection{Linearity}

Calibration graphs were constructed by plotting peak area vs concentration for tramadol hydrochloride and paracetamol. The calibration graphs were plotted concentrations in the range of $0.5-500 \mu \mathrm{g} / \mathrm{ml}$ and $0.5-100 \mu \mathrm{g} / \mathrm{ml}$ for tramadol and paracetamol respectively. The regression line obtained was linear. From the data obtained, corelation coefficient, slope and y-intercept were calculated. The linearity of the method was excellent as evidenced by the correlation coefficient of 0.999 for both drugs. The regression equation and other parameters obtained from the plot are mentioned in Table 1.

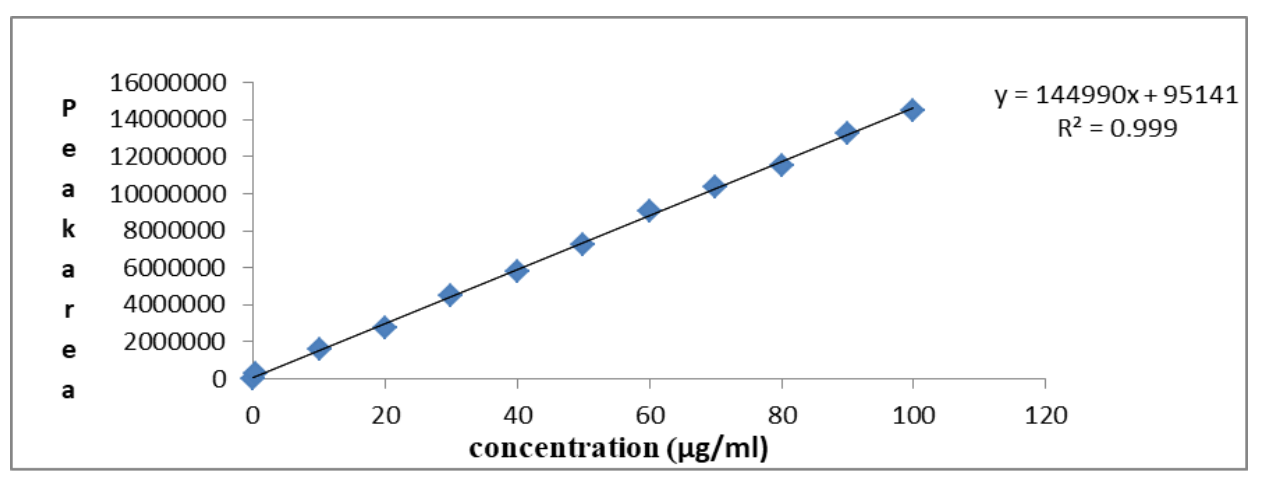

Figure 4 Calibration curve for paracetamol 


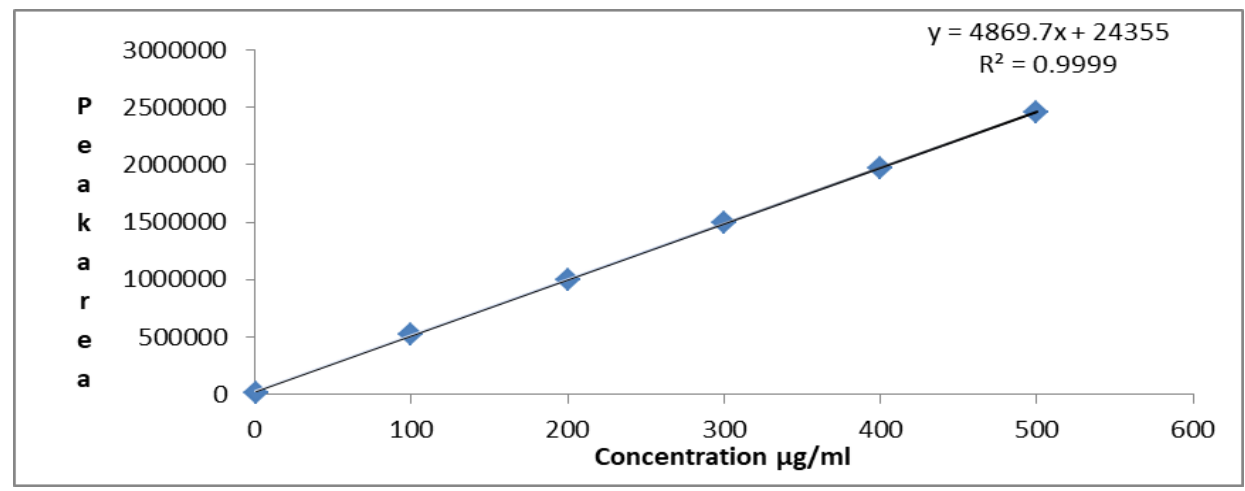

Figure 5 Calibration curve for tramadol hydrochloride

Table 2 Linear regression analysis data

\begin{tabular}{lll}
\hline Parameter & PCM & TRD \\
\hline Linearity & $0.5-100 \mu \mathrm{g} / \mathrm{ml}$ & $0.5-500 \mu \mathrm{g} / \mathrm{ml}$ \\
Regression Equation & $\mathrm{Y}=144990 \mathrm{x}+95141$ & $\mathrm{Y}=4869.7+24355$ \\
Correlation Coefficient & 0.999 & 0.999 \\
\hline
\end{tabular}

\subsubsection{Precision}

Precision was evaluated by injecting six replicate injections of tramadol hydrochloride and paracetamol of sample solution under the same chromatographic conditions and calculated by the \% RSD. The intraday and interday precision study were conducted for both tramadol $\mathrm{HCl}$ and paracetamol. The $\%$ RSD indicates that the developed method is repeatable. The \% RSD for assay of tramadol hydrochloride and paracetamol was found to be 1.72 and 0.36 . The results are shown in Table 3. Both inter-day and intra-day R.S.D. were less than $2 \%$, indicating a sufficient precision of the developed method.

Table 3 Precision studies of tramadol hydrochloride and paracetamol

\begin{tabular}{lllll}
\hline $\begin{array}{l}\text { Amount of std } \\
\text { taken }(\boldsymbol{\mu g} / \mathbf{m l})\end{array}$ & \multicolumn{2}{l}{ Intra-day Precession $(\mathbf{n}=\mathbf{6})$} & \multicolumn{2}{l}{ Inter-day Precession $(\mathbf{n}=6)$} \\
& Mean \pm SD & \%RSD & Mean \pm SD & \%RSD \\
\hline Tramadol & $112602.16 \pm 1795.87$ & 1.59 & $115546 \pm 1224.69$ & 0.88 \\
Hydrochloride & $226174.7 \pm 2690.77$ & 1.18 & $235937.3 \pm 3461.82$ & 1.46 \\
& $346046 \pm 3132.79$ & 0.90 & $364566.5 \pm 3040.94$ & 0.83 \\
\hline Paracetamol & $3145365.17 \pm 27786.33$ & 1.05 & $2151502 \pm 23880.28$ & 1.10 \\
& $6459133 \pm 30278.66$ & 0.46 & $6454137 \pm 27079.26$ & 0.41 \\
& $9362753 \pm 16657.17$ & 0.17 & $9261604 \pm 14805.89$ & 0.15 \\
\hline
\end{tabular}

\subsubsection{Accuracy}

In order to judge the quality and applicability of method the recovery analysis was performed at three levels $80 \%$, $100 \%$, and $120 \%$ by standard addition method. The \% recoveries for Tramadol Hydrochloride and Paracetamol were calculated and it was found to be within the limits; the results are given in Table 4. 
Table 4 Accuracy Data

\begin{tabular}{llllll}
\hline Analyte & \% Level & $\begin{array}{l}\text { Nominal value } \\
\text { (mg) }\end{array}$ & Found (mg) & $\begin{array}{l}\text { Mean\% } \\
\text { Recovery }\end{array}$ & \%RSD \\
\hline \multirow{3}{*}{ Paracetamol } & 80 & 40 & 40.02 & 100.06 & 0.05 \\
& 100 & 50 & 50.02 & 100.14 & 0.20 \\
\hline Tramadol & 120 & 60 & 60.11 & 100.4 & 0.37 \\
Hydrochloride & 100 & 4.6 & 4.57 & 99.34 & 0.21 \\
& 120 & 6.9 & 5.65 & 98.37 & 0.36 \\
& & & 6.87 & 99.66 & 0.17 \\
\hline
\end{tabular}

\subsubsection{Specificity}

Since bulk and tablet formulations are made of different components and excipients, the specificity was carried out through the comparison of the peak retention time of the formulations with paracetamol and tramadol hydrochloride standard drug sample and blank solution. No interference of the excipients was detected since no peak was detected in the same retention time of paracetamol and tramadol hydrochloride.

\subsubsection{Robustness}

The robustness as a measure of method capability to remain unaffected by small, but deliberate changes in chromatographic conditions was studied by testing influence of small changes in mobile phase composition (10\% absolute change in organic phase) and flow rate $( \pm 0.2 \mathrm{~mL} / \mathrm{min})$ and wavelength $( \pm 2 \mathrm{~nm})$. The theoretical plate count and tailing were within the limits. So, the method was found to be robust with respect to variability in all robust conditions. The results are shown in Table 5 and Table 6.

Table 5 Robustness results for paracetamol

\begin{tabular}{llll}
\hline Conditions & \% Assay & \multicolumn{2}{c}{ System Suitability parameters } \\
\cline { 3 - 3 } & & $\begin{array}{l}\text { Theoretical } \\
\text { Plates }\end{array}$ & Tailing Factor \\
\hline Flow Rate $0.8 \mathrm{~mL} / \mathrm{min}$ & 99.68 & 6792 & 1.08 \\
Flow Rate 1.2 mL/min & 99.49 & 6747 & 1.12 \\
Mobile Phase- ACN(60): 1\% Glacial Acetic & 99.67 & 6762 & 1.12 \\
acid(40) & & \\
Mobile Phase- ACN(40): 1\% Glacial Acetic & 99.84 & 6649 & 1.11 \\
acid(60) & & & \\
Wavelength 270 nm & 99.83 & 6839 & 1.12 \\
Wavelength 274 nm & 99.61 & 6869 & 1.12 \\
\hline
\end{tabular}

Table 6 Robustness results for tramadol hydrochloride

\begin{tabular}{lccc}
\hline Conditions & \% Assay & \multicolumn{2}{c}{ System Suitability parameters } \\
\cline { 3 - 3 } & & $\begin{array}{l}\text { Theoretical } \\
\text { Plates }\end{array}$ & Tailing Factor \\
\hline Flow Rate $0.8 \mathrm{~mL} / \mathrm{min}$ & 99.55 & 4665 & 1.21 \\
Flow Rate $1.2 \mathrm{~mL} / \mathrm{min}$ & 99.68 & 4217 & 1.26 \\
Mobile Phase- ACN(60): 1\% Glacial Acetic & 99.83 & 4363 & 1.24 \\
acid(40) & & \\
Mobile Phase- ACN(60): 1\% Glacial Acetic & 99.63 & 4261 & 1.23 \\
acid(40) & & & \\
Wavelength 270 nm & 99.87 & 4107 & 1.23 \\
Wavelength 274 nm & 99.69 & 4316 & 1.24 \\
\hline
\end{tabular}

\subsection{7. $L O D$ and $L O Q$}

The LOD and LOQ of tramadol hydrochloride and paracetamol were determined by using the signal to noise approach as defined in ICH guidelines. The results are given in Table 7. 
Table 7 LOD and LOQ

\begin{tabular}{lll}
\hline Drug & LOD $(\mu \mathrm{g} / \mathrm{ml})$ & LOQ $(\mu \mathrm{g} / \mathrm{ml})$ \\
\hline Tramadol hydrochloride & 0.15 & 0.45 \\
Paracetamol & 0.04 & 0.12 \\
\hline
\end{tabular}

\subsubsection{Ruggedness}

Ruggedness of the developed method was determined by analyzing six sample solutions of by two analysts in the same laboratory to check the reproducibility of the test result. The $\%$ recovery and standard deviation were calculated in both cases. The result was shown in Table 8 .

Table 8 Ruggedness

\begin{tabular}{lll}
\hline Sample & $\begin{array}{l}\text { Analyst - 1 } \\
\text { (Mean } \pm \% \text { RSD) }\end{array}$ & $\begin{array}{l}\text { Analyst-2 } \\
\text { (Mean } \pm \% R S D)\end{array}$ \\
\hline Tramadol HCL & $115546 \pm 1.05$ & $114620.7 \pm 0.96$ \\
Paracetamol & $6454137 \pm 0.41$ & $2641589 \pm 0.19$ \\
\hline
\end{tabular}

\subsubsection{Assay of pharmaceutical formulation}

The proposed validated method was successfully applied to determine tramadol hydrochloride and paracetamol in its tablet dosage form. The result obtained for tramadol hydrochloride and paracetamol was comparable with the corresponding labelled amounts and they are given in Table 9.

Table 9 Analysis of paracetamol and tramadol $\mathrm{HCl}$ in commercial formulation

\begin{tabular}{|c|c|c|c|c|c|c|}
\hline \multirow[t]{2}{*}{ Formulation } & \multicolumn{2}{|c|}{ Labelled claim(mg) } & \multicolumn{2}{|c|}{ Amount found*(mg) } & \multicolumn{2}{|c|}{ \%Recovery* $\%$ RSD } \\
\hline & РCM & TRD & PCM & TRD & PCM & TRD \\
\hline $\begin{array}{l}\text { Calpol T } \\
\text { Tablets }\end{array}$ & 325 & 37.5 & 324.1 & 37.2 & $99.73 \pm 0.34$ & $99.33 \pm 0.26$ \\
\hline
\end{tabular}

\section{Conclusion}

The present work refers to the fact that the most accurate, precise, and robust HPLC method was developed and validated for estimation of tramadol hydrochloride and paracetamol in pharmaceutical dosage form in accordance with the ICH parameters. The method was validated and found to be simple, rapid, accurate, and precise. Percentage of recovery shows that the method is free from interference of the excipients used in the formulation. Therefore, the proposed method can be used for routine analysis of tramadol hydrochloride and paracetamol in its dosage form.

\section{Compliance with ethical standards}

\section{Acknowledgments}

The authors are grateful to Dr. L. Rathaiah, Chairman of Lavu educational society for providing necessary facilities to carry out the above research work.

\section{Disclosure of conflict of interest}

No conflict of interest 


\section{References}

[1] Tripathi KD. (2006). Essentials of Pharmacology, sixth edition, Autocoids and Related drugs, 182.

[2] Rang, D, Ritter, Flower and Henderson. (2007). Rang and Dale's Pharmacology, fifth edition, The Nervous system, Drug dependence drug abuse, 607.

[3] Gharge D and Dhabale P. (2010). Simultaneous estimation of tramadol hydrochloride and paracetamol by UV spectrophotometric method from tablet formulation. International Journal of PharmTech Research, 2, 11191123.

[4] Ahmad M, El-Zinati and Abdel-Latif MS. (2015). Simultaneous determination of paracetamol and tramadol in pharmaceutical tablets by derivative UV-Vis absorption spectrophotometry. Open Analytical Chemistry Journal, 8, 1-6.

[5] Srinivasan KK, Alex J, Shirwaikar AA, Jacob S, Sunilkumar MR and Prabhu SL.(2007). Simultaneous determination of paracetamol and tramadol in pharmaceutical tablets by derivative UV-Vis absorption spectrophotometry. Indian Journal of Pharmaceutical Sciences, 69, 540-545.

[6] Shukla R, Shivkumar R and Shivan KN. (2011). Development of a UV-spectrophotometric method for the simulataneous determination of tramadol hydrochloride and paracetamol in bulk and marketed product. Bulletin of Pharmaceutical Research, 1, 62-66.

[7] Zarei AR, Mardi K and Chalavi S. (2013). Simultaneous spectrophotometric determination of tramadol and acetaminophen in pharmaceutical formulations using H-Point standard addition method. Jordan Journal of Pharmaceutical Sciences, 6, 48-55.

[8] Sawant R, Bhangale L, Joshi R and Lanke P. (2010). Validated spectrophotometric methods for simultaneous estimation of paracetamol, domperidone and tramadol $\mathrm{HCl}$ in pure and tablet dosage form. Journal of Chemical Metrology, 4, 21-27.

[9] Narayan S, Kumar P, Sindhu RK, Tiwari A and Ghosh M. (2009). Simultaneous analysis of paracetamol and tramadol - Analytical method development \& validation. Der Pharma Chemica, 1, 72-78.

[10] Pradip BN, Emanual PM and Guatambhai. (2012). Simultaneous Estimation of Tramadol Hydrochloride, Paracetamol and Domperidone in Pharmaceutical Formulation by Thin-Layer Chromatographic- Densitometric Method. Journal of Chromatography and Separation Techniques, 3(5), 3- 6.

[11] Roosewelt C, Harihrishnan N, Gunasekaran V, Chandrasekaran S, Haribaskar V and Prathap B.(2010). Simultaneous Estimation and Validation of Tramadol and Paracetamol by HPTLC in Pure and Pharmaceutical Dosage Form. Asian Journal of Chemistry, 22(2), 850-854.

[12] Prafulla AP, Mahadev MV and Sunil DR. (2010). Validated HPTLC Method for Simultaneous Quantitation Of Paracetamol, Tramadol And Aceclofenac In Tablet Formulation, Der Pharmacia Lettre, 2(6), 28-36.

[13] Sam Solomon WD, Vijai Anand PR, Rajesh S, Sivakumar R and Venkatnarayanan. (2010). Application of TLCDensitometry Method for Simultaneous Estimation of Tramadol HCl and Paracetamol in Pharmaceutical Dosage Forms; International Journal of Chem Tech Research, 2(2), 1188-1193.

[14] Karunakaran K, Navaneethan G and Elango KP. (2012). Development and Validation of a Stability-Indicating RP-HPLC Method for Simultaneous Determination of Paracetamol, Tramadol $\mathrm{HCl}$ and Domperidone in a Combined Dosage Form. Tropical Journal of Pharmaceutical Research, 11(1), 99-106.

[15] Chandra P, Atul SR, Sathiyanarayanan L and Kakasaheb RM. (2012). Application of HPLC for the Simultaneous Determination of Aceclofenac, Paracetamol and Tramadol Hydrochloride in Pharmaceutical Dosage Form. Scientia Pharmaceutica, 80, 337-351.

[16] Saha S, Dey BK, Chakraborty S and Choudhury T. (2013). Development Of Reverse Phase High Performance Liquid Chromatographic Method And Method Validation Of Paracetamol By Using Economical Single Mobile Phase. Journal of Applied Pharmaceutical Research, 10(1), 24-29.

[17] Swamy DK, Sirisha K,.Dhanuja G and Adukondalu D.(2018). New RP-HPLC method for the simultaneous estimation of paracetamol and tramadol hydrochloride in bulk and tablet dosage form. International Research Journal of Pharmacy, 9(6), 82-86.

[18] Belal T, Awad T and Clark CR. (2009). Determination of Paracetamol and Tramadol hydrochloride in pharmaceutical mixture using HPLC and GC-MS. Journal of Chromatographic Science, 47, 849-854. 
[19] International Conference on Harmonization, Harmonized Tripartite Guideline. (2005). Validation of Analytical Procedures. Text and Methodology. Q2 (R1).

\section{How to cite this article}

Kumar TH, Prajna CKK, Rao KV and Rao YS. (2019). RP-HPLC method for estimation of tramadol hydrochloride and paracetamol in pharmaceutical formulation. GSC Biological and Pharmaceutical Sciences, 8(1), 89-97. 